\title{
Rapidly progressive fatal orbito-cerebral mucormycosis in an immunocompetent patient following entry of an insect into his eye; a case report and literature review
}

\author{
Saleh Mohebbi ${ }^{\circledR}$, Mohammad Mahdi Salem, Hesam Eskandarzadeh, Ayda Sanaei ${ }^{*}$, Mina Jamali \\ 'Department and Research Center for Otorhinolaryngology and Head \& Neck Surgery, Hazrat-e Rasoul Akram Hospital, Iran University of \\ Medical Sciences, Tehran, Iran
}

*Correspondence to

Ayda Sanaei,

Email:

dr_aydasanaei@yahoo.com

Received 2 July 2019 Accepted 30 Nov. 2019 Published online 15 Feb. 2020

Keywords: Mucormycosis, Immunocompetent, Cerebrovascular acciden

\section{Citation: Mohebbi} S, Salem MM, Eskandarzadeh H, Sanaei A, Jamali M. Rapidly progressive fatal orbitocerebral mucormycosis in an immunocompetent patient following entry of an insect into his eye; a case report and literature review. Immunopathol Persa. 2020;6(2):e14. DOI:10.34172 ipp. 2020.14

\begin{abstract}
Mucormycosis, an uncommon and rapidly progressive fungal infection, is mainly seen in immunocompromised patients. However, immunocompetent individuals can also be infected. Here, we present a rapidly progressive orbito-cerebral mucormycosis in an immunocompetent patient, who had a history of entry of an insect into his eye. We report an immunocompetent patient, who had a history of entry of an insect into his eye, presented with left eye panophthalmitis, cellulitis and loss of vision. He underwent orbital exenteration. Then, mucormycosis was diagnosed and amphotericin B was initiated. Left cavernous sinus and internal carotid artery involvement were found in brain magnetic resonance imaging (MRI) and cerebrovascular accident (CVA) was diagnosed. Surgical debridement of necrotic tissue was performed, and postoperatively, our patient died following CVA. Mucormycosis, as a fatal fungal infection, requires early diagnosis, appropriate early surgical and rapid antifungal management so that successful outcome can be achieved.
\end{abstract}

\section{Introduction}

Mucormycosis, an uncommon and rapidly progressive fungal infection, from the Mucorales order, is mainly seen in immunocompromised patients (1). It should be noticed that immunocompetent individuals can also be infected (2). Rhinoorbito-cerebral, cutaneous, pulmonary, gastrointestinal, and disseminated infections are considered to be the clinical presentations of mucormycosis (3). Rhino-orbito-cerebral mucormycosis begins when the fungus affects the nasal mucosa and paranasal sinuses (4). Orbital involvement develops when the orbital wall is invaded through the paranasal sinuses (5), while intracranial invasion is found to occur following progressive ocular involvement (4). We present a rapidly progressive orbito-cerebral mucormycosis in an immunocompetent patient, who had a history of entry of an insect into his eye.

\section{Case Presentation}

A 34-year-old white male patient, who had no evidence of immunodeficiency, and no considerable past medical history, presented with left eye panophthalmitis, cellulitis and loss of vision. He had an episode of entry

\begin{abstract}
Key point
Due to the high-risk conditions of people infected with mucormycosis, early diagnosis, surgical and rapid antifungal management is needed.
\end{abstract}

of an insect to his left eye while riding on motorcycle 25 days earlier. In emergency setting chloramphenicol eye drops BP $0.5 \%$ was administered for him, since no remission was observed after a week. Then he was hospitalized and received high corticosteroid doses accompanied by intravenous (IV) antibiotic, while we do not have any documentation of drug and dosage. $\mathrm{He}$ underwent ethmoidectomy and exploration of the roof of the orbital cavity in that setup however, they reported no evidence of pus or inflammation. Lateral canthotomy and inferomedial decompression of the orbit was performed following the first surgical procedure. Bloody discharge was seen after the operation.

Then, he was referred to our clinic with left eye swelling, proptosis and chemosis (Figure 1). Laboratory investigations revealed; white blood cell (WBC) $12 \times 10^{9}$ per liter, and erythrocyte sedimentation rate (ESR)

\footnotetext{
Copyright (C) 2020 The Author(s); Published by Nickan Research Institute. This is an open-access article distributed under the terms of the Creative Commons Attribution License (http://creativecommons.org/licenses/by/4.0), which permits unrestricted use, distribution, and reproduction in any medium, provided the original work is properly cited.
} 


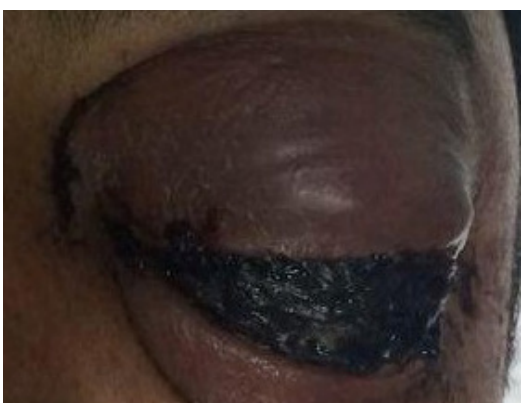

Figure 1. Photograph showing swelling, proptosis, and chemosis of left eye with swelling of left side of the patientıs face.

of $30 \mathrm{~mm} / \mathrm{1}^{\text {st }}$ hour. Vancomycin $1000 \mathrm{mg} / \mathrm{kg} / \mathrm{dd} \mathrm{IV}$ and meropenem $1500 \mathrm{mg} / \mathrm{kg} / \mathrm{d}$ IV were initiated. Exenteration of the left eye was planned due to panophthalmitis, cellulitis and loss of vision. Color change of floor of the orbit and frontal recess was found after exenteration (Figure 2). Color-changed material was resected and sent to pathology lab. The results of pathology showed mucormycosis (Figure 3). Axial and coronal computed tomography (CT) scan of the orbits showed maxillary antrum involvement, erosion of adjacent bones with spread to lamina papyracea, nasal cavity, and inferior orbital fissure (Figure 4). Amphotericin B $50 \mathrm{mg} / \mathrm{kg} / \mathrm{d}$ and caspofungin $50 \mathrm{mg} / \mathrm{m}^{2}$ daily were added to the antibiotics. Three days after the surgery, the patient was taken to an intensive care unit (ICU) following gradually loss of consciousness. Brain magnetic resonance imaging (MRI) showed left cavernous sinus and internal carotid artery involvement and then cerebrovascular accident (CVA) was diagnosed. After a while, surgical debridement of necrotic tissue was performed. Postoperatively, our patient died following CVA.

\section{Discussion}

Mucormycosis, a fungal disease caused by zygomycetes, is appeared to have an acute and fulminant course (5). Although it is an uncommon infection, its incidence is rising $(6,7)$. Mucormycosis usually presents as pulmonary, gastrointestinal, disseminated or rhinocerebral form (8). Earlier publications reported that the pulmonary mucormycosis is the most common form (2). However, a recent study reported the rhino-orbital form as the most frequent (4). Orbital involvement includes infectious spread into the orbital cavity through the paranasal sinuses. This infection can result in vascular thrombosis, including cavernous sinus thrombosis $(1,4,9)$, and ischemia of near tissues, following attachment to the endothelial cells of the vessels (10).

Immunocompromised individuals like patients with malignancies of hematological diseases, long-term corticosteroid consumption, immunosuppressive therapy and HIV infection, are mostly infected. However, there are reports in which immunocompetent individuals are

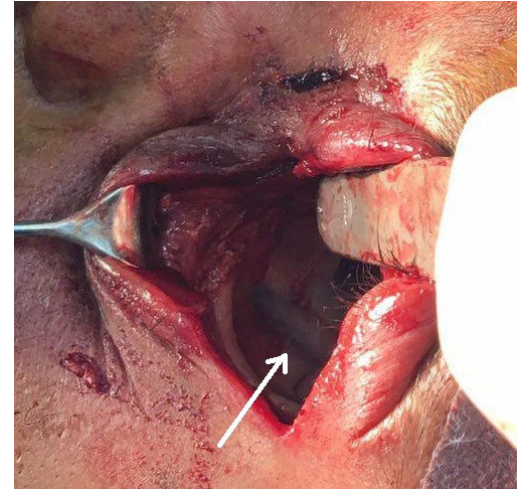

Figure 2. Photograph showing color change of floor of the orbit and frontal recess.

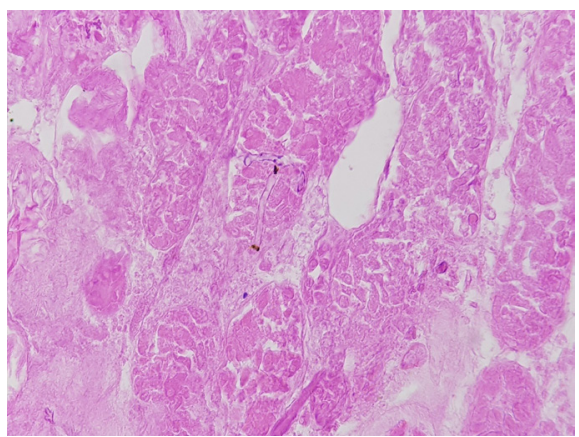

Figure 3. Non-septated hyphae of mucormycosis (arrow) observed under hematoxylin and eosin staining at 100× magnification.

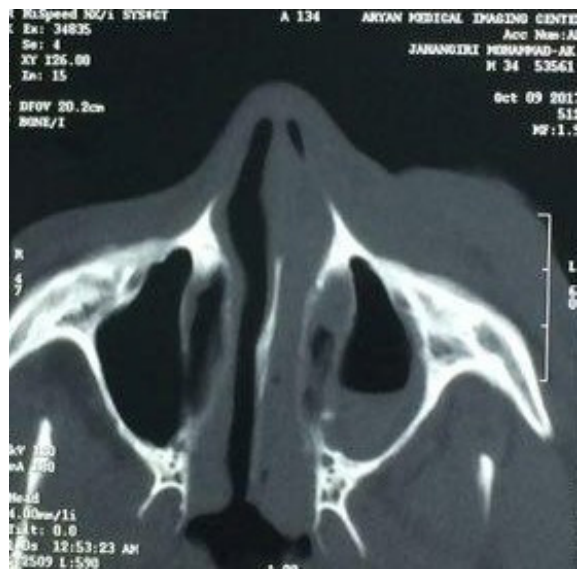

Figure 4. Axial and coronal CT scan of the orbits. Involvement of the maxillary antrum, erosion of the adjacent bones with spread to lamina papyracea, nasal cavity, and inferior orbital fissure are demonstrated.

also infected (2,11-13). Several reports have documented the orbital infection in immunocompetent patients (2, $13,14)$. Rahman et al reported a healthy patient of rhinoorbital mucormycosis who was presented with massive necrosis of the maxilla with retro-bulbar and infra-bulbar involvement. The patient underwent extensive surgical debridement and received medical treatment. However, he 
did not survive and died after ten days (2). Another report of an orbital mucormycosis in a healthy patient, with a history of entry of dust into his left eye and presentation with swelling and redness of the eye, showed that orbital exenteration and intravenous amphotericin $\mathrm{B}$ led to the patient's survival (13). However, up to our knowledge, there are few reports of immunocompetent patients who presented with orbito-cerebral mucormycosis. Anqali et al reported a case of rhino-orbito-cerebral mucormycosis, who presented with a non-healing ulcer on the face and orbital involvement. Their patient died following severe seizures and status epilepticus (15).

There are two cases of orbital mucormycosis which developed following a traumatic laceration from a tree branch to the temporo-parietal scalp and entry of dust particle to the eye $(3,13)$. However, up to our knowledge, there is probably no report of orbito-cerebral mucormycosis following entry of insect into the eye. Our patient had a history of entry of an insect to his left eye and was referred with left eye swelling, proptosis and chemosis. He underwent orbital exenteration. Then, mucormycosis was diagnosed and amphotericin B was initiated. Left cavernous sinus and internal carotid artery involvement were found in brain MRI and CVA was diagnosed. Surgical debridement was performed, and postoperatively, our patient died following CVA. Patient's survival is reported to exceed $80 \%$ when early medical and surgical treatment is performed (16). Badiee et al concluded that effective management of mucormycosis consists of early diagnosis of the disease (13). Similarly, some other reports indicated that early diagnosis and treatment is considered to be important for good prognosis $(3,4,15)$.

\section{Conclusion}

Mucormycosis, as a fatal fungal infection with high mortality rate, requires early diagnosis, appropriate early surgical and rapid antifungal management so that successful outcome is possible. Intracranial involvement is still poor prognosis.

\section{Conflicts of interest}

The authors report no conflicts of interest.

Ethical considerations

Ethical issues (including plagiarism, data fabrication, double publication) have been completely observed by the authors. The patents of the patient gave her informed consent regarding the publication of this case report.

\section{Funding/Support}

No internal or external source of funding was available.

\section{References}

1. Fahrenkopf MP, Nelson JJ, Eichhorn M, Conway J, Hassan A. Rhino-orbital-cerebral mucormycosis and orbital exenteration. Eplasty. 2016;16:ic42.
2. Rahman A, Akter K, Hossain S, Rashid HU. Rhino-orbital mucourmycosis in a non-immunocompromised patient. BMJ Case Rep. 2013;2013:bcr2012007863. doi: 10.1136/bcr2012-007863.

3. Chahal HS, Abgaryan N, Lakshminarayanan R, Glover AT. Orbital mucormycosis following periorbital cutaneous infection. Ophthalmic Plast Reconstr Surg. 2017;33: S146-S148. doi: 10.1097/IOP.0000000000000466.

4. Plowes Hernandez O, Prado Calleros HM, Soberon Marmissolle Daguerre GS, Sadek Gonzalez A. Rhinoorbito-cerebral mucormycosis. Management strategies to avoid or limit intracraneal affection and improve survival. Acta Otorrinolaringol Esp. 2015;66:48-52. doi: 10.1016/j. otorri.2015.01.007.

5. Karadeniz Ugurlu S, Selim S, Kopar A, Songu M. Rhino-orbital mucormycosis: clinical findings and treatment outcomes of four cases. Turk J Ophthalmol. 2015; 45:169-74. doi: 10.4274/ tjo. 82474

6. Santos Gorjon P, Blanco Perez P, Batuecas Caletrio A, Munoz Herrera AM, Sanchez Gonzalez F, de la Fuente Canibano R. Rhino-orbito-cerebral mucormycosis, a retrospective study of 7 cases. Acta Otorrinolaringol Esp. 2010;61:48-53. doi:10.1016/ S2173-5735(10)70008-9

7. Roden MM, Zaoutis TE, Buchanan WL, Knudsen TA, Sarkisova TA, Schaufele RL, et al. Epidemiology and outcome of zygomycosis: a review of 929 reported cases. Clin Infect Disa. 2005; 41:634-53.

8. Brown OE, Finn R. Mucormycosis of the mandible. J Oral Maxillofac Surg. 1986; 44:132-6.

9. Shatriah I, Mohd-Amin N, Tuan-Jaafar TN, Khanna RK, Yunus R, Madhavan M. Rhino-orbito-cerebral mucormycosis in an immunocompetent patient: case report and review of literature. Middle East Afr J Ophthalmol. 2012; 19:258-61. doi: 10.4103/0974-9233.95269

10. Chen YX, He YX, Zhou H, Wang M, Su SO. Rapidly progressive rhino-orbito-cerebral mucormycosis in a patient with type 2 diabetes: A case report. Experiment Therap Med. 2017; 13:1054-6.

11. Haliloglu N, Yesilirmak Z, Erden A, Erden I. Rhino-orbitocerebral mucormycosis: report of two cases and review of the literature. Dentomaxillofac Radiol. 2008; 37:161-6. doi: 10.1259/dmfr/14698002.

12. Karanth M, Taniere $P$, Barraclough J, Murray JA. A rare presentation of zygomycosis (mucormycosis) and review of the literature. J Clin Pathol. 2005; 58:879-81. doi: 10.1136/ jcp.2004.021816

13. Badiee P, Jafarpour Z, Alborzi A, Haddadi P, Rasuli M, Kalani M. Orbital mucormycosis in an immunocompetent individual. Iran J Microbiol. 2012;4:210-4.

14. Fairley C, Sullivan TJ, Bartley P, Allworth T, Lewandowski R. Survival after rhino-orbital-cerebral mucormycosis in an immunocompetent patient. Ophthalmology. 2000; 107:555-8.

15. Angali RK, Jeshtadi A, Namala VA, Gannepalli A. Fatal rhinoorbito-cerebral mucormycosis in a healthy individual. J Oral Maxillofac Pathol. 2014;18:460-3. doi: 10.4103/0973029X.151355

16. Salisbury PL 3rd, Caloss R Jr, Cruz JM, Powell BL, Cole R, Kohut RI. Mucormycosis of the mandible after dental extractions in a patient with acute myelogenous leukemia. Oral Surg Oral Med Oral Pathol Oral Radiol Endod. 1997;83:340-4. 